\title{
Angiotensin II Regulates NOS Expression in Afferent Arterioles of the Developing Porcine Kidney
}

\author{
BRIAN B. RATLIFF, MIROSLAV SEKULIC, JUSTIN RODEBAUGH, AND MICHAEL J. SOLHAUG \\ Department of Physiological Sciences, Eastern Virginia Medical School, Norfolk, Virginia 23501
}

\begin{abstract}
NO protection is crucial against angiotensin II (ANG II) mediated vasoconstriction in postnatal preglomerular resistance vessels. Although whole kidney NOS is developmentally regulated, NOS regulation in developing renal resistance vessels is unknown. The hypothesis was NOS expression and function in developing afferent arterioles are regulated by ANG II through AT1 and AT2 receptors. Afferent arterioles from porcine kidneys, ages newborn, 7, $21 \mathrm{~d}$, and adult, were dissected using a polybead perfusion technique. Dissected afferent arterioles were treated with ANG II and with either the AT1 receptor inhibitor candesartan or the AT2 receptor inhibitor PD 123319 and evaluated for NOS isoform expression and NOS enzymatic activity. Although NOS activity and neuronal NOS (nNOS) expression were greater in the newborn than in the adult, endothelial NOS (eNOS) expression was greater in the adult. ANG II increased NOS activity and eNOS expression at all ages, but nNOS expression only in developing afferents. AT1 and AT2 receptor blockade significantly attenuated NOS activity and eNOS expression at all ages, but nNOS expression only in developing afferents. ANG II regulates nNOS and eNOS expression and NOS activity in afferent arterioles of the developing kidney via AT1 and AT2 receptors.
\end{abstract}

(Pediatr Res 68: 29-34, 2010)

$\mathrm{N}$ ewborn renal hemodynamics is characterized by low renal blood flow (RBF) and GFR (GFR), which both progressively increase with maturation (1-3). During maturation, the immature kidney experiences an $86 \%$ decrease in renal vascular resistance (RVR) and the amount of cardiac output that the kidney receives increases over 8 -fold as RBF increases $(1,4)$. The predominant factor contributing to the newborn's low RBF is high RVR (1-3). Although structural and physical factors play a role in the change in RVR and RBF seen in the developing kidney, an increase in functional vasoactive agents is the main cause for the neonate's enhanced RVR (1-4).

In the adult kidney, the primary site of RVR in the preglomerular vessels occurs in the afferent arterioles (5). Studies involving various species have suggested RVR is further enhanced in the afferent arterioles of the newborn kidney causing functional decreases in RBF, GFR, and filtration fraction, thus, highlighting the hemodynamic significance of enhanced vascular resistance in the newborn's afferent arterioles $(1,6,7)$. The major vasoactive agent that causes the newborn's elevated RVR is the renin-angiotensin system

Received November 19, 2009; accepted March 29, 2010.

Correspondence: Brian Ratliff, Ph.D., Eastern Virginia Medical School, PO Box 1980, Norfolk, VA 23501-1980; e-mail: ratlifbb@gmail.com

Supported by NIH grant 2R01HL52765-04A2 (M.J.S.).
(RAS) (8-11). Many components of the RAS are developmentally regulated in the immature preglomerular resistance vessels. The vasoactive affects of angiotensin II (ANG II) are mediated in the preglomerular vasculature by two receptor subtypes, the AT1 and AT2 receptors, both of which undergo developmentally regulated expression (1,11-14). However, the functions of the two ANG II receptors in the immature kidney have yet to be fully identified.

The two NOS isoforms contributing NO to the newborn's renal hemodynamic state under physiologic conditions are endothelial NOS (eNOS) and neuronal NOS (nNOS), both constitutively expressed within the immature kidney (14-16). Various studies have shown that NO plays a much more pronounced role in the neonate's renal hemodynamics, than in the adult's, and NO counter-balances the highly activated RAS protecting the immature kidney from the deleterious effects of adverse perinatal events that lead to vasomotor acute renal failure $(8,15,17-20)$. In whole kidney models, developmental patterns of eNOS and nNOS are different, suggesting the isoforms have different regulatory factors and functional contributions in the immature kidney $(15,16)$. However, studies designed to investigate the relationship between $\mathrm{NO}$ and ANG II in the preglomerular resistance vasculature have been limited to adult models, thus, leaving the neonate unexamined.

The objective of the study here was to determine the role of ANG II as a regulator of eNOS and nNOS expression and function of NO production in the immature, compared with the mature, preglomerular resistance vessels, primarily the afferent arteriole.

The hypothesis of the study is that in the immature afferent arteriole, NOS expression and function are up-regulated by ANG II through activation of the AT1 and AT2 receptors.

\section{MATERIALS AND METHODS}

Animals. All experiments involving animal usage fulfilled AVMA guidelines and were approved by the Institutional Animal Care and Use Committee (IACUC) at Eastern Virginia Medical School. The animal study protocol was in accordance with the National Institutes of Health Guide for the Care and Use of Laboratory Animals.

These experiments used afferent arterioles obtained from kidney slices from ages representative of the developmental spectrum including newborns, 7-, 21-d-old piglets, and adults (NB, 7D, 21D, and AD, respectively) $(n=$ 10/age group). All experiments were performed on mixed breed swine

Abbreviations: ANG II, angiotensin II; RAS, renin-angiotensin system; AT1X, AT1 inhibition; AT2X, AT2 inhibition; RBF, renal blood flow; RVR, renal vascular resistance; NB, newborn; 7D, 7-day-old; 21D, 21day-old; AD, adult 


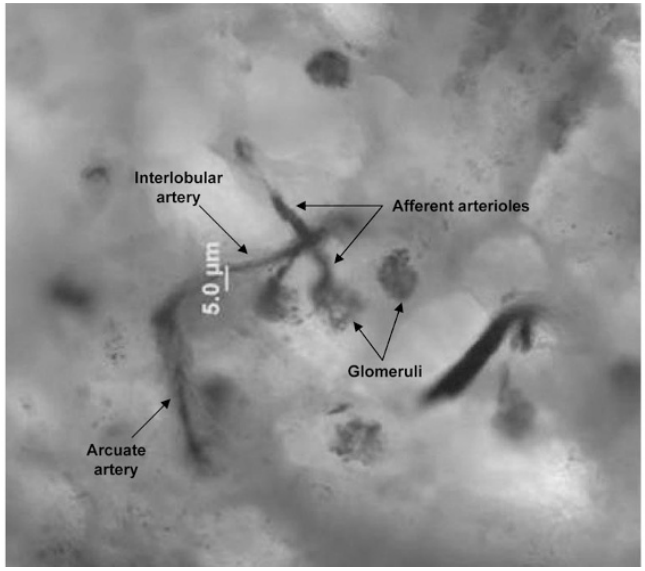

Figure 1. Magnification $(50 \times)$ of a porcine 7D corticomedullary kidney slice stained with perfused blue-dyed polybeads.

obtained from the same local vendor (Smithfield, VA). Left kidneys of preweanling piglets (newborns and 7D) were harvested on arrival. Left kidneys of weaned piglets (21D) and adults older than $70 \mathrm{~d}$ of age were harvested $24 \mathrm{~h}$ after arrival to allow for dietary and climatic adjustment.

Preparation. Animals were initially anesthetized with intramuscular ketamine (adults, $10 \mathrm{mg} / \mathrm{kg}$; piglets, $5 \mathrm{mg} / \mathrm{kg}$ ), followed by a sacrificial i.v. euthasol infusion $(50 \mathrm{mg} / \mathrm{kg}$ ) (Delmorva Laboratories, Midlothian, VA). The left kidney was exposed through a retroperitoneal flank incision, and a catheter was placed in the proximal renal artery for intrarenal perfusion.

Microdissection of renal afferent arterioles. The techniques here are modified from previous publication $(21,22)$. Left kidneys were initially perfused with PBS (Invitrogen, Carlsbad, CA), followed by perfusion of $3 \mathrm{~mL}$ of PBS containing polybead polystyrene blue-dyed microspheres $0.2-10 \mu \mathrm{m}$ in diameter (Polysciences, Warrington, PA). Kidneys were excised, decapsulated, and collecting systems were removed. Kidneys were sectioned into 500 $\mu \mathrm{m}$ coronal slices (Maclwain Chopper, Mickle Laboratory, Philadelphia, PA) (Fig. 1) and digested with $2 \mathrm{mg} / \mathrm{mL}$ collagenase (Sigma Chemical Co.). Digested slices were placed in DMEM (Invitrogen) containing protease inhibitors and $0.1 \mu \mathrm{M}$ candesartan (Astra Zeneca, Sweden) for AT1 receptor inhibition (AT1X), $0.1 \mu \mathrm{M}$ PD 123319 (Sigma Chemical Co.) for AT2 receptor inhibition (AT2X), or medium alone (control and ANG II). Kidney slices were maintained at $4^{\circ} \mathrm{C}$ during microdissection on the dissecting microscope stage. Manual dissection of afferent arterioles included using dissecting forceps, iris scissors, and 33-gauge stainless steel needles. For optimal expression and enzymatic activity results, dissecting time was restricted to $1.5 \mathrm{~h}$, as determined by preliminary experiments here (not shown) and by Mattson and Fu (21). During dissection, $20 \mathrm{~mm}$ of microvessel was obtained per sample. Dissected afferent arterioles were obtained near the juxtaglomerular axis to ensure homogenous consistency between all samples analyzed.

mRNA and protein expression assay. Dissected microvessels were incubated in Krebs buffer (Sigma Chemical Co.) for either $1 \mathrm{~h}$ (mRNA study) or for $8 \mathrm{~h}$ (protein study) with $0.1 \mu \mathrm{M}$ ANG II (Sigma Chemical Co.), $0.1 \mu \mathrm{M}$ candesartan, and $0.1 \mu \mathrm{M}$ ANG II, $0.1 \mu \mathrm{M}$ PD 123319 and $0.1 \mu \mathrm{M}$ ANG II, or medium alone. At the conclusion of the incubation period, microvessels were homogenized by sonication, mRNA was isolated using the RNeasy Kit (Qiagen, Valencia, CA), and protein was used for western blots.

Real-time RT-PCR. Isolated mRNA was subject to real-time RT-PCR, as previously described (13). In brief, the LightCycler (Roche, NY) was used for all real-time PCR reactions using the LightCycler FastStart DNA Master SYBR Green I amplification kit (Roche). Polymerase amplification was carried out for 40 cycles. At the onset of expression experiments, PCR products were sequenced to ensure product specificity. Primers (Invitrogen) used were specific for nNOS, eNOS, and 18s rRNA. Primers sequences and Genbank accession numbers are described elsewhere (13). The 18s rRNA was used as internal control for gene expression of NOS isoforms. The expression of $18 \mathrm{~s}$ rRNA is an effective internal reference because it does not undergo significant regulation in the postnatal immature kidney.

Western blot analysis. Western blots were performed on afferent arteriole homogenates, as previously described $(15,16)$. In brief, $10 \mu \mathrm{g}$ of arteriole protein homogenates, as measured by Bradford Protein Assay (Bio-Rad, Hercules, CA), were separated by SDS-PAGE, blotted onto nitrocellulose (Hy-Bond, Amersham, Arlington Heights, IL), and blocked with nonfat dry milk. Blots were incubated with antibodies specific for porcine eNOS (Santa
Cruz, Santa Cruz, CA) and nNOS (Abcam, Cambridge, MA), followed by incubation with horseradish-peroxidase-conjugated secondary antibody ( $\mathrm{Ab}$ cam) and detected by enhanced chemiluminescence (Amersham). Samples were normalized to $\beta$ tubulin (Santa Cruz).

NOS activity assay. NOS activity was measured as the conversion of $\mathrm{L}-{ }^{3} \mathrm{H}$-arginine to $\mathrm{L}-{ }^{3} \mathrm{H}$-citrulline in afferent arterioles, as described previously (23). Briefly, arterioles were incubated in buffer containing $\mathrm{L}-{ }^{3} \mathrm{H}$-arginine for $1 \mathrm{~h}$. Included in the incubation buffer were $0.1 \mu \mathrm{M}$ ANG II, $0.1 \mu \mathrm{M}$ candesartan with $0.1 \mu \mathrm{M}$ ANG II, or $0.1 \mu \mathrm{M}$ PD 123319 with $0.1 \mu \mathrm{M}$ ANG II. At the conclusion of the incubation period, the amount of $\mathrm{L}^{3}{ }^{3} \mathrm{H}$-arginine converted to $\mathrm{L}^{3} \mathrm{H}$-citrulline in buffer was measured [after separation by Dowex resin (Bio-Rad)]. Data are expressed as picomoles of $\mathrm{L}-{ }^{3} \mathrm{H}$-arginine converted to $\mathrm{L}-{ }^{3} \mathrm{H}$-citrulline per minute per $\mathrm{mg}$ of protein minus any activity not inhibited by NOS inhibitors, with adjustment for background levels. Background levels were determined in heat-inactivated samples and represent free tritium or noncationic tritiated species not separated by Dowex resin. Total counts available for conversion were determined by $100 \%$ standard prepared without Dowex resin purification. Pelletized microvessels removed from the NOS activity assay were used in a Bradford Protein Assay (Bio$\mathrm{Rad})$, to assess the amount of microvessels in each sample.

Statistical analysis. Results obtained for NOS expression and enzymatic activity are expressed as means \pm SEM. For multiple comparisons between various ages and effect of treatment, a two-way ANOVA with Bonferroni's posttest was performed using GraphPad Prism version 4.00 for Windows (GraphPad, San Diego, CA). Differences were considered significant at $p<$ 0.05 .

\section{RESULTS}

Successful staining of the preglomerular vasculature using polybead perfusion is illustrated in Fig. 1.

We initially ran an ANG II dose dependent trial on newborn dissected afferent arterioles to determine the optimal concentration of ANG II to use in subsequent NOS experiments. eNOS and nNOS mRNA expression and NOS enzymatic activity progressively increased with increased ANG II concentration, with the exception of eNOS mRNA expression, which reached maximum expression at concentration $10^{-7} \mathrm{M}$ with no further increase in expression with increased ANG II concentration (Fig. 2). NOS activity and mRNA expression demonstrated significant reduction when ANG II concentrations were below $10^{-7} \mathrm{M}$.

Basal expression of eNOS mRNA and protein in afferent arterioles demonstrated similar patterns. The eNOS mRNA and protein expression were minimal immediately after birth in the newborn and 7D, but with continued vascular maturity, NOS expression progressively increased in the 21D before reaching maximal levels in the adult afferent arteriole (Fig. 3). In contrast to the observed pattern for eNOS expression, nNOS mRNA and protein basal expression were enhanced in the period immediately after birth in the newborn and 7D afferents (Fig. 4). After 7 d, both nNOS mRNA and protein expression decreased in the $21 \mathrm{D}$ before reaching minimal levels of expression in the adult afferents. NOS activity coincided with nNOS, not eNOS, mRNA and protein expression patterns, as shown by the results of the NOS enzymatic activity assay (Fig. 5) in which NOS activity was significantly elevated in the immediate newborn period before decreasing to its lowest levels observed in the adult afferent arterioles.

On ANG II treatment, afferent arterioles responded by increasing eNOS mRNA expression to $175 \%$ in the newborn and $156 \%$ in the adult afferent, an effect that was blocked by both AT1 and AT2 receptor inhibition (Fig. 6). However, while eNOS protein expression was also increased during ANG II treatment, enhanced protein expression was not sig- 

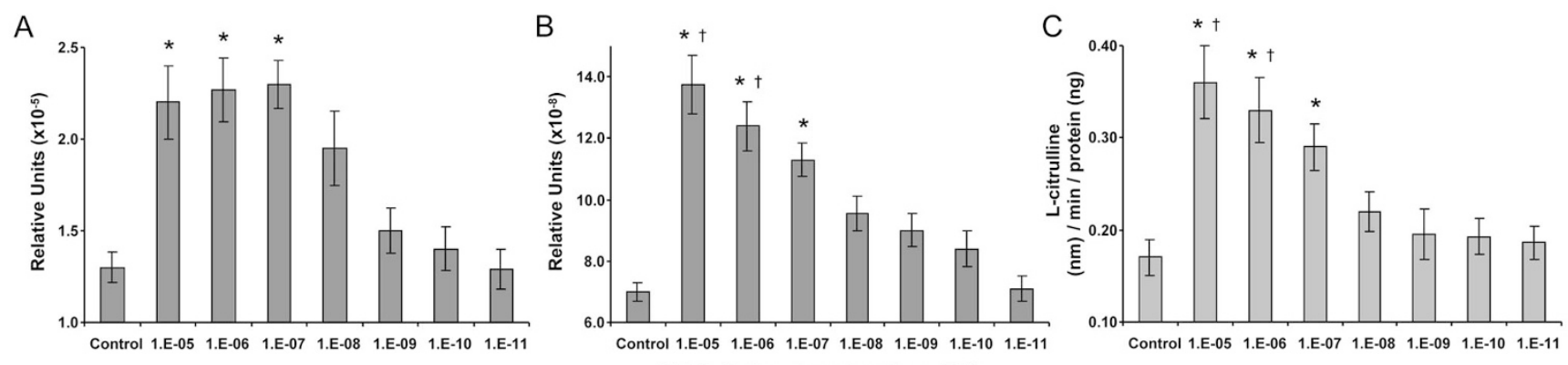

ANG II Concentration (M)

Figure 2. ANG II dose response trial in newborn afferent arterioles regarding NOS mRNA expression. $A$, eNOS; $B$, nNOS; $C$, NOS enzymatic activity. ${ }^{*} p<$ 0.05 , vs control, 1e-9, 1e-10, 1e-11; $\dagger p<0.05$, vs $1 \mathrm{e}-8$.

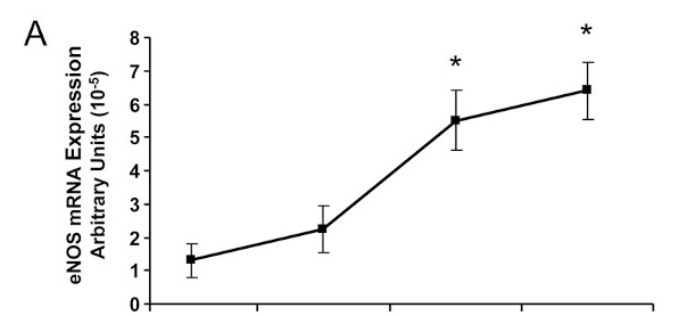

B

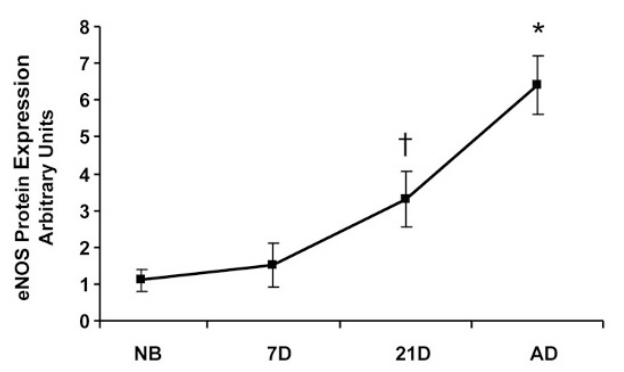

Figure 3. Basal expression of eNOS in afferent arterioles. A, eNOS mRNA expression as measured by real-time PCR. $B$, eNOS protein expression as measured by western blot. $* p<0.05$, vs NB, 7D, 21D; $\dagger p<0.05$, vs NB.

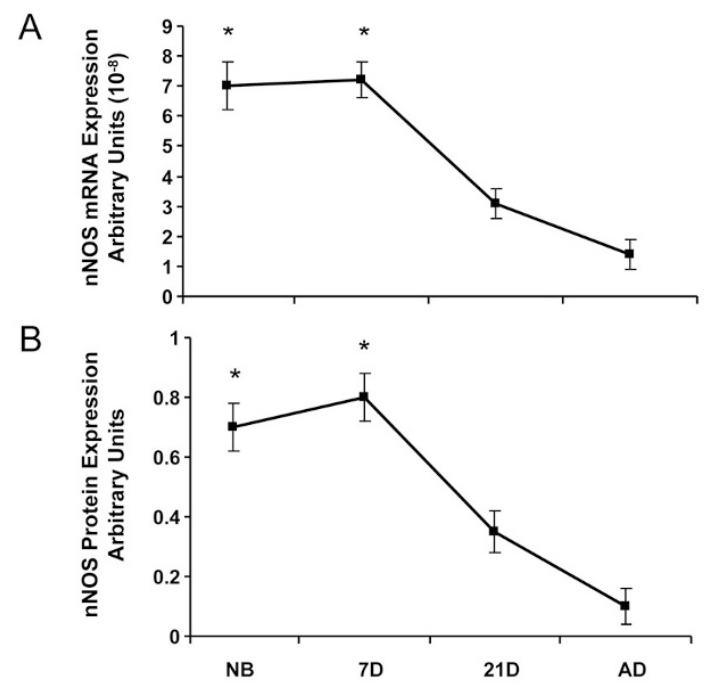

Figure 4. Basal expression of nNOS in afferent arterioles. $A$, nNOS mRNA expression as measured by real-time PCR. $B$, nNOS protein expression as measured by western blot. ${ }^{*} p<0.05$ vs $21 \mathrm{D}$, AD.

nificant in the newborn (expression was $120 \%$ as compared with basal protein expression) and required further vascular maturity of the afferent before ANG II induced significant

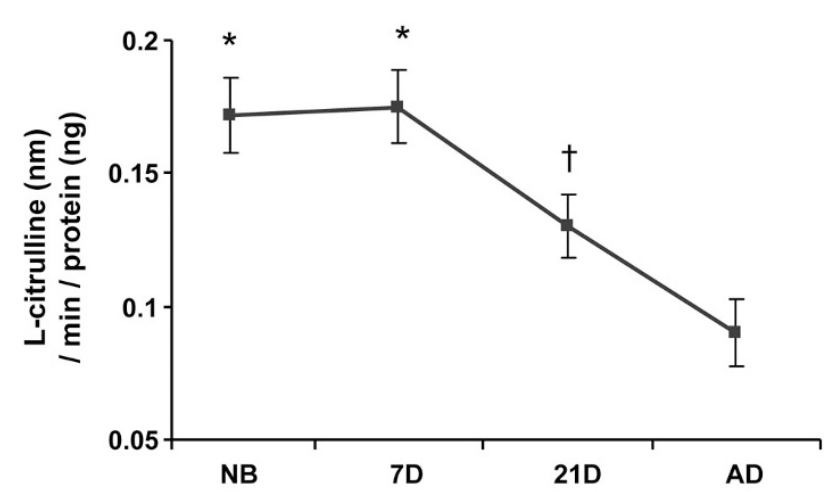

Figure 5. Basal NOS enzymatic activity in afferent arterioles as measured by the production of $\mathrm{NO}$ by quantification of ${ }^{3} \mathrm{H}$-L-arginine converted to ${ }^{3} \mathrm{H}-\mathrm{L}$ citrulline during enzymatic activity assay. ${ }^{*} p<0.05 v s 21 \mathrm{D}, \mathrm{AD} ; \dagger p<0.05$, vs $\mathrm{AD}$.

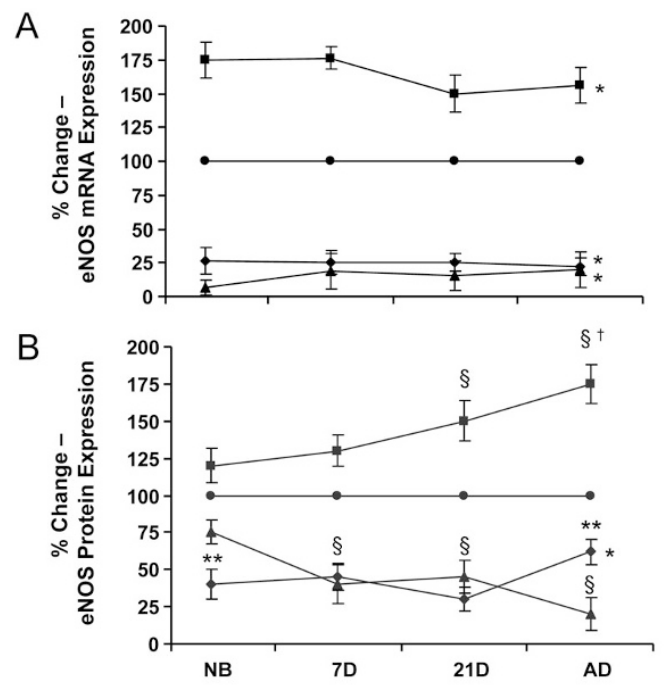

Figure 6. The percent change in eNOS expression in afferent arterioles in controls (@) and after treatment with ANG II (ם), ANG II with candesartan (AT1X: A) or ANG II with PD 123319 (AT2X $\bullet$ ). A, eNOS mRNA expression as measured by real-time PCR, $B$, eNOS protein expression as measured by western blot. ${ }^{*} p<0.05 v s$ control (all ages); $\$ p<0.05 v s$ control; $\dagger p<0.05 v s$. NB, 7D; **p $<0.05 v s$ AT1X.

up-regulation of eNOS protein, as observed in the adult where expression was $175 \%$. ANG II effects on eNOS protein expression demonstrated minimal regulation in the newborn's afferent arterioles via the AT1 receptor, but AT1 receptor 

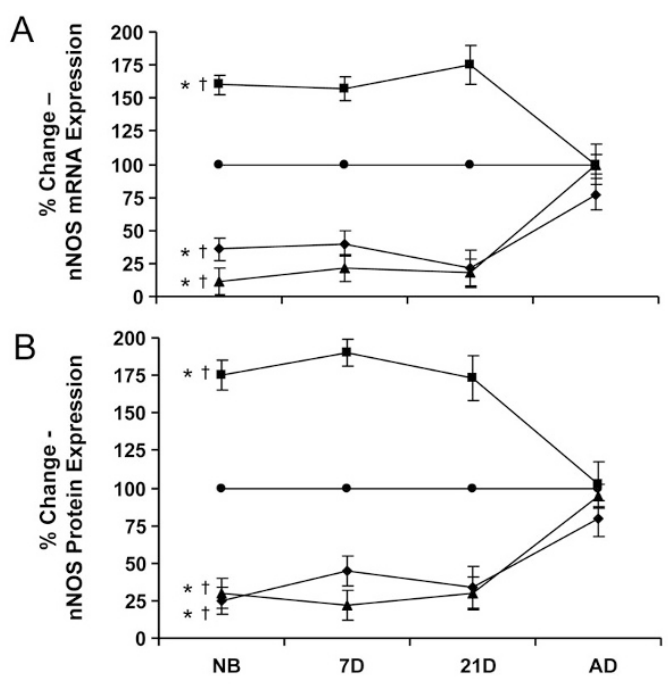

Figure 7. The percent change in nNOS expression in afferent arterioles in controls $(\bullet)$ and after treatment with ANG II (ם), ANG II with candesartan (AT1X: $\Delta$ ) or ANG II with PD 123319 (AT2X: ). A.) nNOS mRNA expression as measured by real-time PCR, $B$.) nNOS protein expression as measured by western blot. ${ }^{*} p<0.05$ vs control (all ages except AD); $\uparrow p<$ 0.05 vs $\mathrm{AD}$ (all ages).

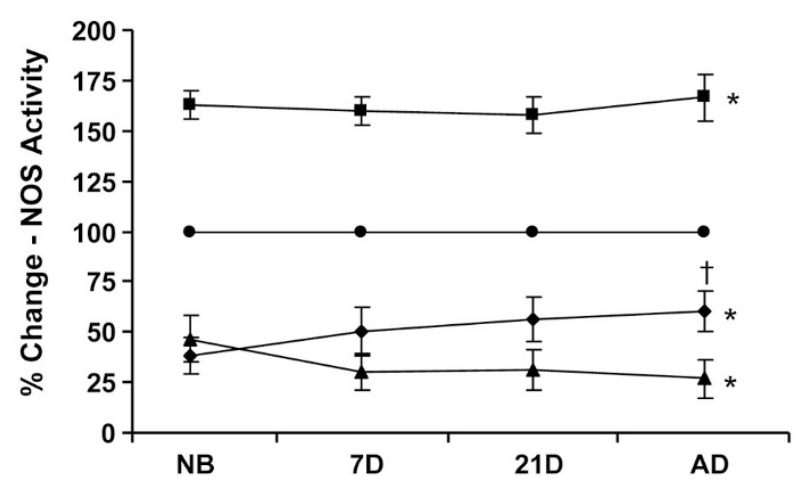

Figure 8. The percent change in NOS enzymatic activity in afferent arterioles (as measured by enzymatic assay) in controls (-) and after treatment with ANG II (ם), ANG II with candesartan (AT1X: $\mathbf{\Delta}$ ) or ANG II with PD 123319 (AT2X ). ${ }^{*} p<0.05 v s$ control (all ages); $\dagger p<0.05 v s$ AT1X.

modulation of ANG II regulation increased with continued maturation, while eNOS protein expression regulation via the AT2 receptor was initially elevated in the newborn before attenuation with continued maturation.

Immediately after birth, ANG II significantly up-regulated both eNOS mRNA expression (160-175\%) and protein (175$190 \%$ ) in the afferent arterioles of the newborn, 7D, and 21D (Fig. 7). Blockade of either the AT1 or AT2 receptor resulted in significant blunting of both nNOS mRNA and protein in the developing afferent arterioles, suggesting their role in ANG II mediated nNOS regulation in neonate afferent arterioles. However, once arterioles were mature, ANG II had no effect on nNOS mRNA and protein expression, as observed in the afferents of the adult kidney. Furthermore, inhibition of either the AT1 or AT2 receptor in the adult did not illicit a significant reduction in nNOS mRNA or protein, suggesting ANG II does not regulate nNOS via the AT1 nor AT2 receptor of the afferent arteriole in the adult.
Regardless of eNOS and nNOS expression patterns, NOS enzymatic activity was enhanced equivalently (160-170\% increased activity) with ANG II treatment at all ages studied (Fig. 8). After birth, modulation of ANG II regulated NOS activity by the AT1 receptor progressively increased, whereas AT2 receptor mediated regulation slowly diminished, with continued maturation. The treatment of afferent arterioles with either AT1 or AT2 inhibitors alone without ANG II had comparable effects on NOS isoform expression and activity as when inhibitors were introduced to arterioles in the presence of ANG II (not shown). These findings suggest nNOS may be the main contributor to NOS activity in the period immediately after birth, while eNOS assumes the role as main contributor of NOS activity in the adult, with a coordinated transition between the two enzymes during the process of maturation in the afferent arteriole.

\section{DISCUSSION}

Despite reports by Thompson and Weiner (24) that indicate adaptations in the sensitivity of vascular smooth muscle to NO increases after birth, RBF remains low in the newborn due to the enhanced vasoconstrictor response of the RAS $(8-11)$. To counter-balance the elevated RAS of the newborn and to maintain adequate RBF and GFR, studies have demonstrated a crucial enhanced role of NO in the neonate's renal hemodynamic state. In 1993, Solhaug et al. (19) demonstrated intrarenal perfusion of the NOS inhibitor L-NAME caused greater changes in RVR, RBF and GFR in the piglet than in the adult. Furthermore, Sener and Smith $(18,25)$ demonstrated L-NAME administration leads to an increase in RVR, a decrease in RBF and a reduction of GFR by $50 \%$ in the newborn lamb, an affect that was attenuated as the newborn lamb matured. In 1996, Ballevre et al. also demonstrated an enhanced role of NO in the neonate when NOS inhibition with L-NAME in newborn rabbits increased RVR by $31 \%$, whereas decreasing RBF by $20 \%$ and GFR by $13 \%$ (17).

More recent studies have further linked ANG II to regulation of neonatal NOS expression and activity. In the neonate, nNOS has a developmental pattern similar to that of renin producing cells suggesting an interaction between the vasoconstriction of the RAS and the vasodilation effects of NOS $(14,26)$. Solhaug et al. (11) demonstrated preperfusion of an AT1 receptor inhibitor before NOS inhibition with L-NAME renal perfusion blunted the effects of L-NAME in the newborn, but not the adult, kidney. Ratliff et al. (27) demonstrated AT1 receptor inhibition in the newborn piglet attenuated glomerular eNOS expression. However, information on NOS regulation is much more available in the adult. For instance, experiments by various groups have identified both nNOS and eNOS isoforms in the afferent arterioles of the adult rat $(14,21,28,29)$. Patzak et al. observed augmented contraction of almost 25\% in afferent arterioles by ANG II when NOS was inhibited (30). Patzak et al. and Thorup et al. $(31,32)$ both found ANG II administration increased NO production by $8-10 \%$ in adult afferent arterioles, whereas the ANG II induced increase in NO production was abolished upon blockade of the AT1 receptor (31). Furthermore, Patzak et al. (30) 
demonstrated ANG II vasoconstrictor response in adult mice afferent arterioles is enhanced by $10 \%$ in eNOS knockout mice. Hennington et al. (33) observed intrarenal ANG II infusion increases eNOS mRNA by $70 \%$ in adult rat kidneys.

Results here indicate ANG II up-regulated both eNOS and nNOS mRNA and protein expression in the immature afferent arterioles. ANG II ability to up-regulate eNOS protein was minimal in the newborn, possibly due to maximum cellular capacity to generate increased eNOS protein, thus increasing the need for an alternative source of NO, possibly from increased nNOS expression. Indeed, mRNA and protein expression patterns of nNOS in both whole kidney studies (15) and here using isolated afferent arterioles are very similar to the developmental pattern of NOS activity, suggesting nNOS may be responsible for the enhanced NOS activity in the newborn. Both nNOS expression and NOS activity are enhanced in the neonate, in contrast to eNOS expression, which is significantly reduced in the newborn. Blockade of either AT1 or AT2 receptor attenuated eNOS and nNOS mRNA and protein expression and NOS activity in the immature afferent arterioles, a finding in agreement with the reports in the adult (31).

In contrast to findings here, a study on newborn porcine arteries by Baranov and Armstead (34) indicated ANG II primarily elicits dilation via the AT1 and not the AT2 receptor. However, Baranov and Armstead used pial arteries from the porcine cerebrovascular system, a vascular system different from the renal preglomerular resistance vasculature. Chappellaz and Smith (35) measured RBF changes in the renal artery during systemic injection of AT1 and AT2 receptor inhibitors in lambs and observed ANG II modulates RVR through activation of AT1, but not AT2 receptors. Although Chappellaz and Smith's approach determined whole kidney $\mathrm{RBF}$ modulation by $\mathrm{ANG}$ II receptors, it failed to take in account the regulation of NOS activity by specific segments of the renal vasculature, such as the afferent arteriole, which may have functional differences compared with the rest of the renal vasculature. Furthermore, there may be differences in vascular response with regard to species.

A contributing factor to ANG II regulation of NOS expression/activity and vasoactivity in the afferent arterioles that may account for differences observed between developmental age, vascular beds, or species may be attributed to differences in the local expression of AT1 and AT2 receptors (in addition to possible differences in receptor coupling) in the vessels. Ratliff et al. (14) demonstrated vast differences in expression of AT1 and AT2 receptors in the afferent arterioles of the newborn and adult, and also between afferent arterioles and other arteries within the kidney. Ratliff et al. (14) and others have reported AT1 receptor protein increases while AT2 receptor protein decreases in the preglomerular vasculature with continued maturation after birth $(12,13)$. Although our results here show attenuation of NOS mRNA and protein during AT1 and AT2 inhibition in the immature afferent arterioles, inhibition of either receptor in the adult had no significant effect on nNOS expression. In accord with receptor developmental expression patterns of ANG II receptors in the developing afferent arteriole, here we show NOS activity regulation by the AT1 receptor increases while AT2 receptor regulation decreases during maturation.

Although nNOS expression was similar to the developmental pattern of NOS activity, regulation of nNOS expression was slightly different from regulation of NOS activity by ANG II receptors during the immature period (NB through $21 \mathrm{~d}$ ) and into adulthood. Indeed, these results are unexpected but may suggest crosstalk and coordinated changes between the ANG II receptor subtypes, thus leading to compensatory mechanisms between the two receptors relating changes in NOS expressional and activity during maturation. The notion of crosstalk between the two receptors is also suggested by the expression patterns of the receptors in the afferent arteriole during maturation, as reported by Ratliff et al. (14). Maternal humoral factors still present in the newborn after birth may play an important role in the developmental and coordinated changes observed in the preglomerular vasculature of the developing neonate.

ANG II may modulate NOS enzymatic activity through various pathways. AT1 receptor activation stimulates multiple mechanisms that increase intracellular calcium concentration including the opening of cell membrane calcium channels, activation of phospholipase $\mathrm{C}$ and $\mathrm{IP}_{3}$ formation, release of calcium from internal stores, and activation of protein kinase $\mathrm{C}$ (PKC). Calcium forms a complex with calmodulin and binds to NOS enzymes thus displacing inhibitory mechanisms on both eNOS and nNOS enzymes rendering the enzymes' catalytic activity functional. ANG II activation of AT1 and AT2 receptors also results in a cascade of events that include the phosphorylation and activation of various kinases including Akt, p38 MAPK, AMPK, cAMP-dependent protein kinase (PKA), MAPK kinase, and other MAPKs, all of which lead to increased phosphorylation of NOS and increased NOS catalytic activity (36-38).

ANG II may influence NOS expression through various pathways. The nNOS gene contains potential binding sites for transcription factors such as AP-2, transcriptional enhancer factor-a/M-CAT binding factor, CREB, ATF, Ets, NF-1, and $\mathrm{NF}-\kappa \mathrm{B}$ (39), whereas the eNOS promoter contains consensus sequences for the binding of transcription factors AP-1, AP-2, NF-1, NF- $\kappa$ B, and CREB (39). Stimulation of ANG II receptors activates various MAPKs including ERK1/2 and p38 MAPK, which leads to phosphorylation of AP-1 and induction of c-fos and c-jun, and activation of CREB leading to increased binding of transcription factors to NOS promoter sequences causing an increase in NOS transcription.

On the basis of results here, we conclude eNOS and nNOS expression and NOS functional activity in the immature afferent arteriole is regulated by ANG II through the AT1 and AT2 receptors. Furthermore, developmental patterns of NOS expression and activity suggest nNOS is the crucial enhanced isoform that provides counter-balancing NO vasodilation thus opposing augmented RAS vasoactivity characteristic of newborn renal hemodynamics.

\section{REFERENCES}

1. Gruskin AB, Edelman CM Jr, Yuan S 1970 Maturational changes in renal blood flow in piglets. Pediatr Res 4:7-13 
2. Kleinman LI, Lubbe RJ 1972 Factors affecting the maturation of glomerular filtration rate and renal plasma flow in the newborn dog. J Physiol 223:395-409

3. Jose PA, Logan AG, Slotkoff LM, Lilienfield LS, Calcagno PL, Eisner GM 1971 Intrarenal blood flow distribution in canine puppies. Pediatr Res 5:335-344

4. Evan AP Jr, Stoeckel JA, Loemker V, Baker JT 1979 Development of the intrarenal vascular system of the puppy kidney. Anat Rec 194:187-199

5. Spitzer A, Edelmann CM Jr 1971 Maturational changes in pressure gradients for glomerular filtration. Am J Physiol 221:1431-1435

6. Aperia A, Broberger O, Herin P, Joelsson I 1977 Renal hemodynamics in the perinatal period, A study in lambs. Acta Physiol Scand 99:261-269

7. Ito S, Johnson CS, Carretero OA 1991 Modulation of angiotensin II-induced vasoconstriction by endothelium-derived relaxing factor in the isolated microperfused rabbit afferent arteriole. J Clin Invest 87:1656-1663

8. Osborn JL, Hook JB, Bailie MD 1980 Regulation of plasma renin in developing piglets. Dev Pharmacol Ther 1:217-228

9. Pelayo JC, Eisner GM, Jose PA 1981 The ontogeny of the renin-angiotensin system. Clin Perinatol 8:347-359

10. Wallace KB 1980 Postnatal development of the renin-angiotensin system in rats. Am J Physiol 238:R432-R437

11. Solhaug MJ, Wallace MR, Granger JP 1996 Nitric oxide and angiotensin II regulation of renal hemodynamics in the developing piglet. Pediatr Res 39:527-533

12. Gomez RA, Lynch KR, Chevalier RL, Wilfong N, Everett A, Carey RM, Peach MJ 1988 Renin and angiotensinogen gene expression in maturing rat kidney. Am J Physiol 254:F582-F587

13. Ciuffo GM, Viswanathan M, Seltzer AM, Tsutsumi K, Saavedra JM 1993 Glomerular angiotensin II receptor subtypes during development. Am J Physiol 265:F264F271

14. Ratliff B, Rodebaugh J, Sekulic M, Dong KW, Solhaug M 2009 Nitric oxide synthase and renin-angiotensin expression and NOS function in the postnatal renal resistance vasculature. Pediatr Nephrol 24:355-365

15. Solhaug MJ, Dong XQ, Adelman RD, Dong KW 2000 Ontogeny of neuronal nitric oxide synthase, NOS I, in the developing porcine kidney. Am J Physiol Regul Integr Comp Physiol 278:R1453-R1459

16. Solhaug MJ, Kullaprawithaya U, Dong XQ, Dong KW 2001 Expression of endothelial nitric oxide synthase in the postnatal developing porcine kidney. Am Physiol Regul Integr Comp Physiol 280:R1269-R1275

17. Ballevre L, Thonney M, Guignard JP 1996 Nitric oxide modulates glomerula filtration and renal blood flow of the newborn rabbit. Biol Neonate 69:389-398

18. Sener A, Smith FG 2002 Glomerular and tubular responses to N(G)-nitro-L-arginine methyl ester are age dependent in conscious lambs. Am J Physiol Regul Integr Comp Physiol 282:R1512-R1520

19. Solhaug MJ, Wallace MR, Granger JP 1993 Endothelium-derived nitric oxide regulates renal hemodynamics in the developing piglet. Pediatr Res 34:750-754

20. Torok J, Gerova M 1996 Vascular responses after long-term inhibition of nitric oxide synthesis in newborn dogs. Physiol Res 45:323-328

21. Mattson DL, Wu F 2000 Nitric oxide synthase activity and isoforms in rat renal vasculature. Hypertension 35:337-341

22. Pelayo JC, Mobilia M, Tjio S, Singh R, Nakamoto JM, Van Dop C 1994 A method for isolation of rat renal microvessels and mRNA localization. Am J Physiol 267:F497-F503
23. Xiao S, Erdely A, Wagner L, Baylis C 2001 Uremic levels of BUN do not cause nitric oxide deficiency in rats with normal renal function. Am J Physiol Renal Physiol 280:F996-F1000

24. Thompson LP, Weiner CP 1996 Acetylcholine relaxation of renal artery and nitric oxide synthase activity of renal cortex increase with fetal and postnatal age. Pediat Res 40:192-197

25. Sener A, Smith FG 2001 Renal hemodynamic effects of L-NAME during postnata maturation in conscious lambs. Pediatr Nephrol 16:868-873

26. Fischer E, Schnermann J, Briggs JP, Kriz W, Ronco PM, Bachmann S 1995 Ontogeny of NO synthase and renin in juxtaglomerular apparatus of rat kidneys. Am J Physiol 268:F1164-F1176

27. Ratliff B, Rodebaugh J, Sekulic M, Solhaug M 2007 Glomerular eNOS expression during postnatal maturation and AT1 receptor inhibition. Pediatr Nephrol 22:11351142

28. Bachmann S, Bosse HM, Mundel P 1995 Topography of nitric oxide synthesis by localizing constitutive NO synthases in mammalian kidney. Am J Physiol 268:F885F898

29. Terada Y, Tomita K, Nonoguchi H, Marumo F 1992 Polymerase chain reaction localization of constitutive nitric oxide synthase and soluble guanylate cyclase messenger RNAs in microdissected rat nephron segments. J Clin Invest 90:659-665

30. Patzak A, Mrowka R, Storch E Hocher B, Persson PB 2001 Interaction of angiotensin II and nitric oxide in isolated perfused afferent arterioles of mice. J Am Soc Nephrol 12:1122-1127

31. Patzak A, Lai EY, Mrowka R, Steege A, Persson PB, Persson AE 2004 AT receptors mediate angiotensin II-induced release of nitric oxide in afferent arterioles. Kidney Int 66:1949-1958

32. Thorup C, Kornfield M, Goligorsky MS, Moore LC 1999 AT1 receptor inhibition blunts angiotensin II stimulated nitric oxide release in renal arteries. J Am Soc Nephrol 10:S220-S224

33. Hennington BS, Zhang H, Miller MT 1998 Angiotensin II stimulates synthesis of endothelial nitric oxide synthase. Hypertension 31:283-288

34. Baranov D, Armstead WM 2005 Nitric oxide contributes to AT2 but not AT1 angiotensin II receptor-mediated vasodilation of porcine pial arteries and arterioles. Eur J Pharmacol 525:112-116

35. Chappellaz ML, Smith FG 2007 Systemic and renal hemodynamic effects of the AT1 receptor antagonist, ZD 7155, and the AT2 receptor antagonist, PD 123319, in conscious lambs. Pflugers Arch 453:477-486

36. Michell BJ, Chen Z, Tiganis T, Stapleton D, Katsis F, Power DA, Sim AT, Kemp BE 2001 Coordinated control of endothelial nitric-oxide synthase phosphorylation by protein kinase $\mathrm{C}$ and the cAMP-dependent protein kinase. $\mathrm{J}$ Biol Chem 276:17625-17628

37. Jiang JG, Chen RJ, Xiao B, Wang JN, Wang Y, Cowart LA, Xiao X, Wang DW, Xia Y 2007 Regulation of endothelial nitric oxide synthase activity through phosphorylation in response to epoxyeicosatrienoic acids. Prostaglandins Other Lipid Mediat 82:162-174

38. Gorin Y, Kim NH, Feliers D, Bhandari B, Choudhury GG, Abboud HE 200 Angiotensin II activates Akt/protein kinase B by an arachidonic acid/redoxdependent pathway and independent of phosphoinositide 3-kinase. FASEB J 15:1909-1920

39. Forstermann U, Boissel JP, Kleinert H 1998 Expressional control of the constitutive isoforms of nitric oxide synthase (NOS I and NOS III). FASEB J 12:773-790 